\title{
Freezing Thawing Resistance of Concrete Incorporating Glass Waste
}

\author{
Raed Abendeh ${ }^{1}$, Khaled Ramadan ${ }^{2}$, Rami Haddad ${ }^{3} \&$ Mousa Bani Baker ${ }^{1}$ \\ ${ }^{1}$ Al-Zaytoonah university of Jordan, Amman, Jordan \\ ${ }^{2}$ Applied Science University, Amman, Jordan \\ ${ }^{3}$ Jordan University of science and Technology, Irbid, Jordan \\ Correspondence: Raed Abendeh, Al-Zaytoonah university of Jordan, Amman, Jordan. E-mail: \\ r.abendeh@zuj.edu.jo
}

Received: July 4, 2015 Accepted: July 15, 2015 Online Published: August 13, 2015

doi:10.5539/jmsr.v4n4p19 URL: http://dx.doi.org/10.5539/jmsr.v4n4p19

\begin{abstract}
Glass waste, which is dumped around the world in huge amounts, can be used as a partial replacement of mineral aggregate in concrete industry. This would not only contribute to reducing pollution extent but also enhancing physical properties and durability of concrete. This article reports the mechanical performance of concrete with different replacement percentages of crushed glass waste of cement or fine aggregates before and after being subjected to standard cycles of freezing and thawing. Mechanical performance was evaluated in terms of compressive and flexural strengths. Furthermore, internal damage extent was evaluated using ultrasonic pulse velocity and dynamic modulus of elasticity. The results (average of six specimens for each test) revealed the feasibility of incorporating glass waste in concrete mixtures for the purpose of improving strength and durability; especially in environments where concrete is being exposed to an effective freezing and thawing cycles.
\end{abstract}

Keywords: glass waste, freeze-thaw cycles, non-destructive tests

\section{Introduction}

Glass waste is one among many waste materials used in concrete industry. Since glass is a non-organic material made by sintering selected raw materials, thus cannot be incinerated or decomposed. Glass recycling can reduce the complete reliance on natural aggregate resources and decrease the generated environmental waste (green solution).

Glass waste can be used in construction industry as a partial replacement of fine aggregate or/and as a partial replacement of Portland cement (glass powder). Pattengill and shutt (1973) were the first who used the grounded powdered glass as pozzolanic material to replace the cement partially (Pattengil \& Shutt, 1973).Various research works have tackled the topic of incorporating glass waste in concrete mixtures to establish a ground for its usage in concrete industry (Kim et al., 2014; Bazant \& Mayer, 1998; Saikia \& de Brito, 2014; Madandoust \& Ghavidel, 2013; Tuan, Hwang, Lin, Chen, \& Young, 2013; Saribiyik, Piskin,\& Saribiyik, 2013; Ling, Poon, \& Wong, 2013; Soroushian, 2012; Ismail \& Al-Hashmi, 2009; Federico \& Chidiac, 2009; Taha \& Nounu, 2008; Shi \& Zheng, 2007; Topcu \& Canbaz, 2004; Metwally, 2007; Schmidt \& Saia, 1963; Carpenter \& Cramer, 1999; American Psychological Association, 1972). Expansive reactions between amorphous silica (from glass) and alkalis from cement have been noticed to cause disintegration of concrete structures. Bazant and Mayer (1998) found that the glass particle sizes to have a great an impact on glass-alkalis reactivity ; stipulating that using particles of sizes of around 1.5 $\mathrm{mm}$ would lead to excessive expansion whereas using sizes less than $0.25 \mathrm{~mm}$ would have negligible negative impact on concrete behavior; agreeing with the findings by Carpenter and Cramer (Carpenter \& Cramer, 1999).

Freeze-thaw cycles (F/T) may cause deterioration of concrete; especially in concrete structures exposed continuously to water such as water tanks and seashore structures. The accumulative effects of freeze-thaw action throughout successive winter seasonsmay disruption both paste and aggregate leading to their expansion and crackingleading ultimately to scaling and crumbling of the concrete.One of the few studies thattackled durability aspect of glass waste concrete was that of Kim et al (2014) which revealed that utilizing waste glass sludge as a partial replacement of cement can improve the resistance of concrete to $(\mathrm{F} / \mathrm{T})$ cyclesin absence orpresence of deicing salts.

A preliminary study has been overtaken to assess the potential of replacingcement or fine aggregate by glass waste in concrete. Different percentages of crushed and powder glass of up to $20 \%$ with an increment of $5 \%$ were 
incorporated into concrete. Concrete specimens without and with glass waste replacements were subjected to $\mathrm{F} / \mathrm{T}$ action of up to 230 cycles using ASTM test method C666 (plan A). Compressive and flexural strengths measurements were acquired before and after exposure to different F/T cycles along with resonance frequency and ultrasonic. Obtained data were analyzed to determine optimal replacement ratios.

\section{Materials}

Natural crushed fine and coarse limestone aggregates and ordinary Portland cement (OPC) were used in preparing different concrete mixes. Coarse aggregate at a maximum aggregate size of $12.5 \mathrm{~mm}$ was used along with fine aggregates having a fineness modulus of 2.8. The physical properties for coarse and fine aggregates and mineral filler were determined according to ASTM specifications: results are summarized in Table 1.

Table 1. The aggregate properties used in the research

\begin{tabular}{lcccc}
\hline $\begin{array}{l}\text { Aggregate type } \\
\text { (limestone) }\end{array}$ & $\begin{array}{c}\text { ASTM test } \\
\text { designation }\end{array}$ & $\begin{array}{c}\text { Bulk specific } \\
\text { gravity }\end{array}$ & $\begin{array}{c}\text { Apparent } \\
\text { specific gravity }\end{array}$ & $\begin{array}{c}\text { Absorption } \\
\text { percentage }\end{array}$ \\
\hline Coarse & C 127 & 2.5 & 2.52 & 4.5 \\
Fine & C 128 & 2.47 & 2.485 & 7 \\
Mineral filler & C 128 & 2.515 & 2.534 & \\
\hline
\end{tabular}

The waste glass was obtained from crushing and milling bottles and window glass which is referred toas Soda-lime glass type; the gradation of which is shown in Table 2. The sizes of crushed glass used as a partial replacement of fine aggregate were between $4.75 \mathrm{~mm}$ and $0.075 \mathrm{~mm}$, whereas, the sizes of those used as a partial replacement of cement wereless than $0.075 \mathrm{~mm}$.

Table 2. Sieve analysis gradations of the crushed waste glass

\begin{tabular}{lccc}
\hline Sieve size & \% passing (mid point) & \% retained & \% cumulative retained \\
\hline $3 / 4 "(19.5 \mathrm{~mm})$ & 100 & 0 & 0 \\
$1 / 2 "(12.5 \mathrm{~mm})$ & 95 & 5 & 5 \\
$3 / 8 "(9.5 \mathrm{~mm})$ & 88 & 7 & 12 \\
$\# 4(4.76 \mathrm{~mm})$ & 51 & 37 & 49 \\
$\# 8(2.36 \mathrm{~mm})$ & 31 & 20 & 69 \\
$0.85 \mathrm{~mm}$ & 11 & 20 & 89 \\
$0.425 \mathrm{~mm}$ & 6 & 5 & 94 \\
$0.075 \mathrm{~mm}$ & 2 & 4 & 98 \\
pan & & 2 & 100 \\
\hline
\end{tabular}

\section{Experimental Work and Test Methods}

\subsection{Mixture Proportions}

To achieve the main objective of this research, a total of eight concrete mixtures were prepared to determine the impact of replacing fine aggregates and cement by crushed and milled glass wastes, respectively, on mechanical properties and durability of concrete subjected to freezing-thawing cycles: glass waste replaced fine aggregates at percentages of $5 \%, 10 \%, 15 \%$ and $20 \%$ and cement at percentages of $5 \%, 10 \%$, and $15 \%$. The basic concrete mixture (without waste glass) had a water-to-cement ratio (w/c) of 0.5 , and a proportion by weight for fine and coarse aggregates of 1.75 and 3.25 respectively. A superplasticizer was used whenever needed to maintain a slump value above $70 \mathrm{~mm}$.

\subsection{Test Methods}

\subsubsection{Specimens Preparation and Testing}

For each type of test and type of mixture, six specimens were prepared. Control mixtures and those with glass replacements were cast in molds consisting of 75-mm cubes and prisms $(75 \times 75 \times 300 \mathrm{~mm})$ before de-molded then cured under standard conditions for 28 days. The cubes were designated for determining compressive according to 
(BS 1881 Part 108). The prisms, on the other hand, where tested for flexural strength according to ASTM test method C78, resonance frequency according to ASTM test method C215- 14, and ultrasonic pulse velocity according to ASTM test method C 597 -09. These measurements were carried out prior and after exposing concrete to varying cycling of $\mathrm{F} / \mathrm{T}$ up to 350 . The letter $\mathrm{F}$ have been used to designate concrete mixtures that incorporated glass as replacements of fine aggregate whereas the letter P designated those prepared with glass waste powder replacements of the cement.

\subsubsection{Freezing and Thawing Test}

Specimens were subjected to repeated freezing and thawing cycles according to ASTM C666 (procedure A) during a total period of 2.5 hours according to the scheme of schematic of Figure 1.

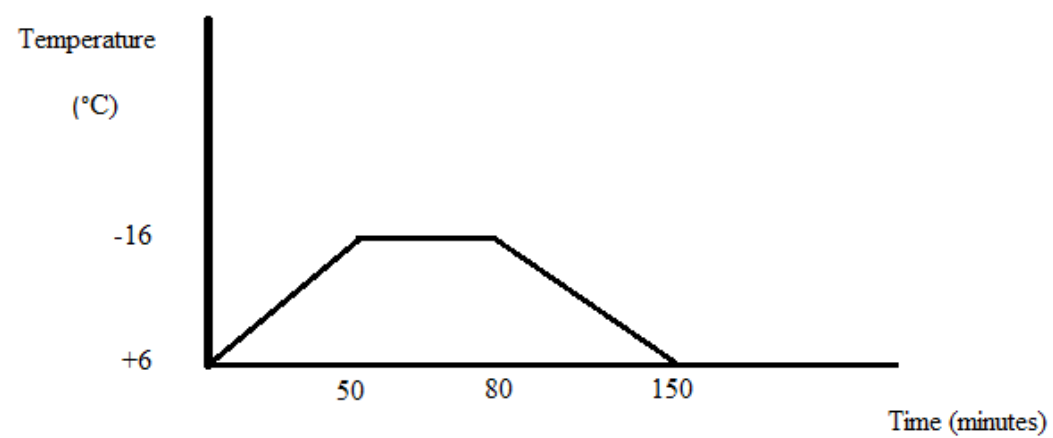

Figure 1. Freezing and thawing repeated cycle used in the experimental work 3.6.2 Adverse Events

\section{Results and Discussion}

The results and discussed in different subsections. The results (average of six specimens) related to loss in weight of concrete specimens upon $\mathrm{F} / \mathrm{T}$ cycles are reported first. After that, measurements of compressive and flexural strengths are reported and discussed in sections 4.2 and 4.3 respectively. Finally, damage induced in different concrete specimens was evaluated nondestructively as reported in section 4.4.

\subsection{Weight Loss in Concrete Prisms under F/T Effect}

Figure 2 shows the weight loss percentage of concrete specimens due to surface scaling by cycles of freezing and thawing. The results showed that the use of glass waste contributed significantly to decreasing surface scaling of concrete, whether that was through replacement of fine aggregate or cement. The decrease in surface scaling was more pronounced in mixtures with cement replacements by glass waste powder; suggesting that some pozzolanic activity between the glass and hydrated cement might have taken place; confirming the findings by Kim et al. (2014).

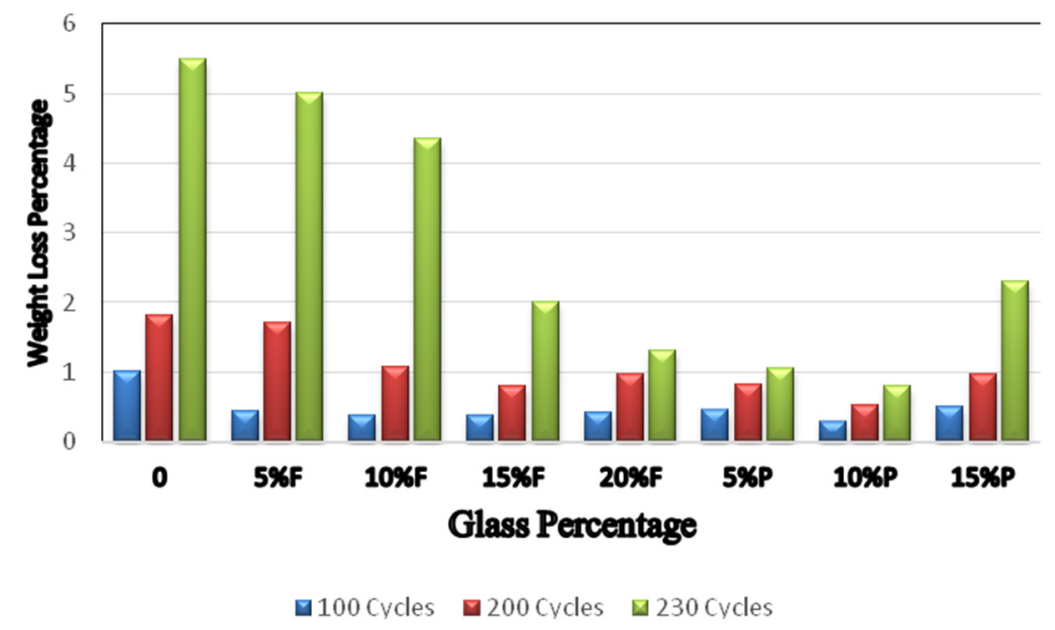

Figure 2. Weight loss percentage of concrete prisms containing different glass percentages at 100, 200 and $230 \mathrm{~F} / \mathrm{T}$ cycles (results are average of six specimens at each percentage) 


\subsection{Compressive and Flexural Strengths}

Figure 3 also shows compressive strength results of different concrete prisms containing different glass waste percentages and subjected to freezing and thawing cycles up to 230 cycles, as compared to control specimens. The results showed that incorporation of glass waste in concrete had contributed to enhancing compressive strength; owning to possible improvement of pore system by transformation of calcium hydroxide to calcium silica hydrate as a result of pozzolanic nature of the glass waster. Concrete mixtures, incorporated waster glass at percentages greater than $5 \%$, showed better resistance than that of those prepared without glass waste replacement of sand or cement. The residual compressive strength after 230 cycles reached as high as $48 \%$ for mixtures with glass waster replacement as compared to about $34 \%$ to control mixture. As may be expected, the performance of the concrete mixtures under $\mathrm{F} / \mathrm{T}$ action was better for specimens with glass waste replacement of fine aggregate as compared to that of those with glass waste replacement of cement.

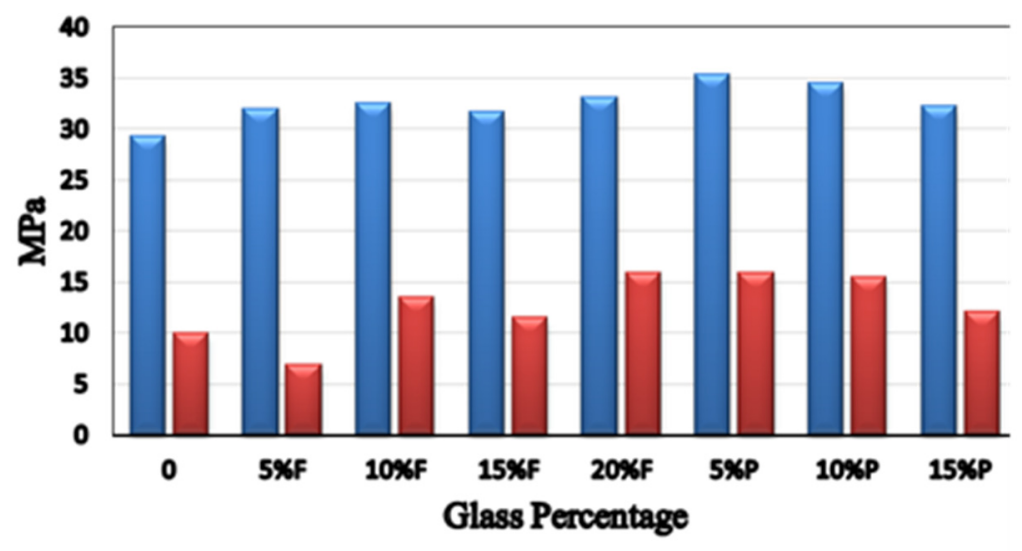

घ0 cycle $\square 230$ cycles

Figure 3. Compressive strength of concrete cubes containing glass waste at different replacement percentages of fine aggregate or cement; before and after exposure to $230 \mathrm{~F} / \mathrm{T}$ cycles (results are average of six specimens at each percentage)

Figure 4 shows the flexural strength for mixtures containing $0 \%, 5 \%, 10 \%$, and $15 \%$ of crushed glass waste as a partial replacement of fine aggregate and $5 \%, 10 \%$ and $15 \%$ of milled glass as a partial replacement of cement content. It can be seen that the flexural strength of the concrete increased slightly in almost all mixtures containing glass waste as compared to that without replacements. After exposure to $230 \mathrm{~F} / \mathrm{T}$ cycles, concrete prisms, containing glass waste powder at $5-10 \%$ as partial replacement of cement content contributed the most to maintaining flexural strength. This can be related to the pozzolanic characteristics of the powder glass, hence the lower permeability of concrete containing glass waste (Pattengil \& Shutt, 1973; Kim et al., 2014; Bazant \& Mayer, 1998).

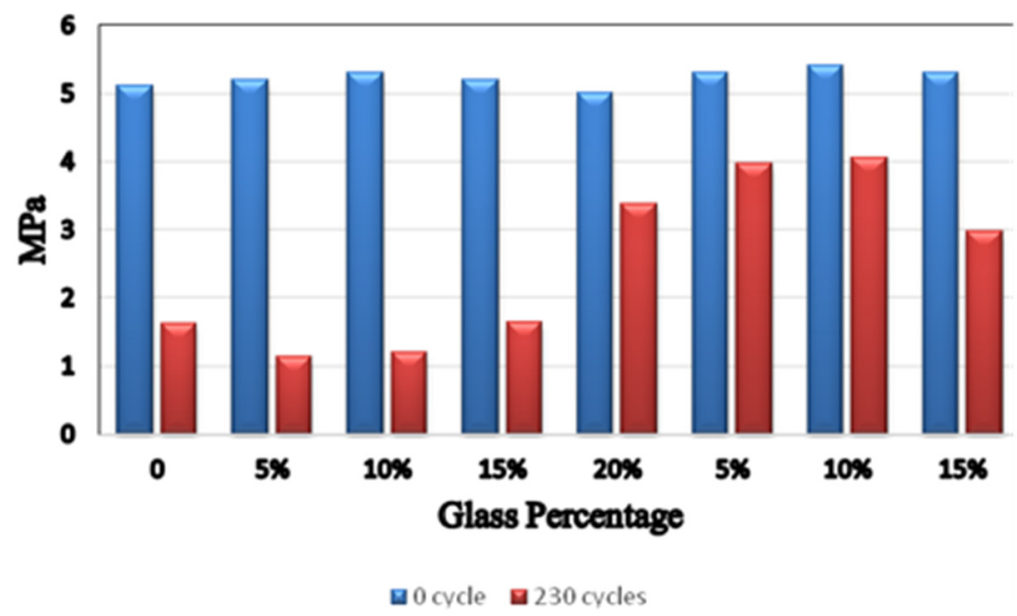

Figure 4. Flexural strength of concrete prisms containing glass waste at different replacement percentages of fine aggregate or cement; before and after exposure to $230 \mathrm{~F} / \mathrm{T}$ cycles(results are average of six specimensat each

percentage) 


\subsection{Nondestructive Tests Results}

The damage induced in various concrete mixtures under different $\mathrm{F} / \mathrm{T}$ cycles was evaluated using two nondestructive techniques, namely ultrasonic pulse velocity and resonance frequency. Based on these measurements, certain damage indices were computed and used for evaluating the impact of replacing cement or fine aggregate with glass waste in concrete on its resistance to freezing and thawing.

\subsubsection{Ultrasonic Velocity Method}

The damage index in terms of UPV, was computed using Equation (1) as follows:

$$
D I_{U P V}=1-\left(\frac{U P V^{d a m}}{U P V^{o}}\right)^{2}
$$

Where, $U P V^{o}$ is the initial ultrasonic pulse velocity and $U P V^{d a m}$ is the ultrasonic pulse velocity after certain number of $\mathrm{F} / \mathrm{T}$ cycles.

Figure 5 depicts damage index in terms of ultrasonic pulse velocity versus number of freezing thawing cycles for concrete prisms, prepared with varying glass waste replacement of cement and fine aggregates. The results showed that exposing concrete to up to $100 \mathrm{~F} / \mathrm{T}$ cycles had imparted limited cracking, hence damage in various mixtures. However, the damage index in various concrete mixtures showed a drastic increase upon exposure to $\mathrm{F} / \mathrm{T}$ cycles equal to or greater than 200. It is rational to conclude that mixtures incorporated glass waste as replacement of cement at percentages of 10 and $15 \%$ were the least to be damaged by $200 \mathrm{~F} / \mathrm{T}$ cycles. In general, various prisms were significantly damaged at $230 \mathrm{~F} / \mathrm{T}$ cycles without positive contribution of glass replacement of either cement or fine aggregates.

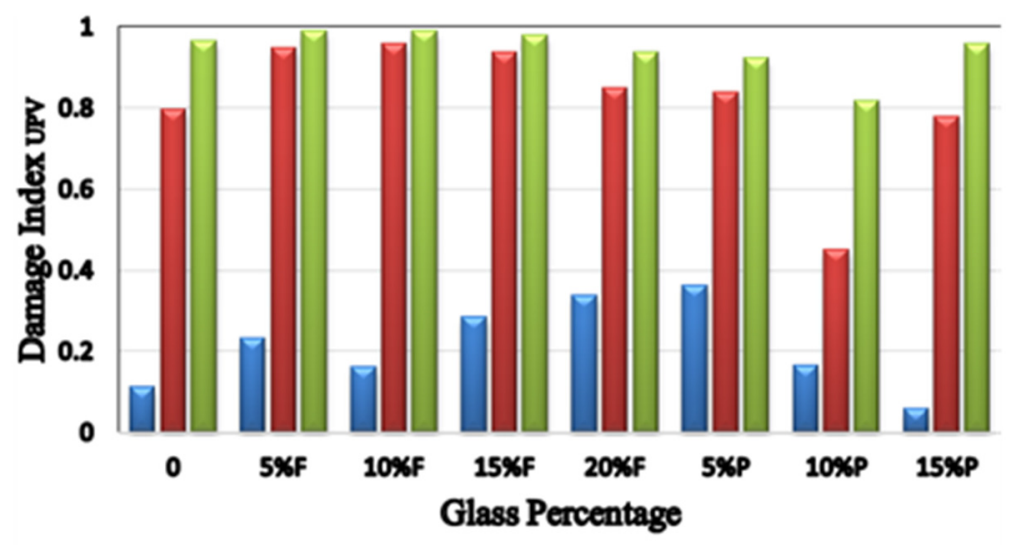

田 $100200 \mathbf{\square} 230$

Figure 5. Damage index in terms of UPV versus percentage replacement of glass waster in concrete (results are average of six specimens at each percentage)

\subsubsection{Resonance Frequency}

As well stipulated, resonance frequency is a nondestructive test that enables computing the dynamic modulus of elasticity for concrete. Accordingly, a damage index in terms of the initial dynamic modulus of elasticity, $D I_{D M E}$, is written as:

$$
D I_{D M E}=1-\frac{\left(E_{d}\right)_{d a m}}{\left(E_{d}\right)_{0}}
$$

Where, $\left(E_{d}\right)_{o}$ are the initial dynamic elastic modulus whereas $\left(E_{d}\right)_{d a m}$ is the dynamic elastic modulus for prisms exposed to $\mathrm{F} / \mathrm{T}$ cycles.

Figure 6 depicts the damage index, as defined by Equation (2), versus glass waste replacement percentage of cement and fine aggregates after prisms exposure to $230 \mathrm{~F} / \mathrm{T}$ cycles. The least damage index was obtained in 
concrete mixture containing $10 \%$ of glass waste powder as a partial replacement of cement content with mixtures incorporating $5-15 \%$ of glass waste as replacement of cement content showing higher damage indices than that of control ones.

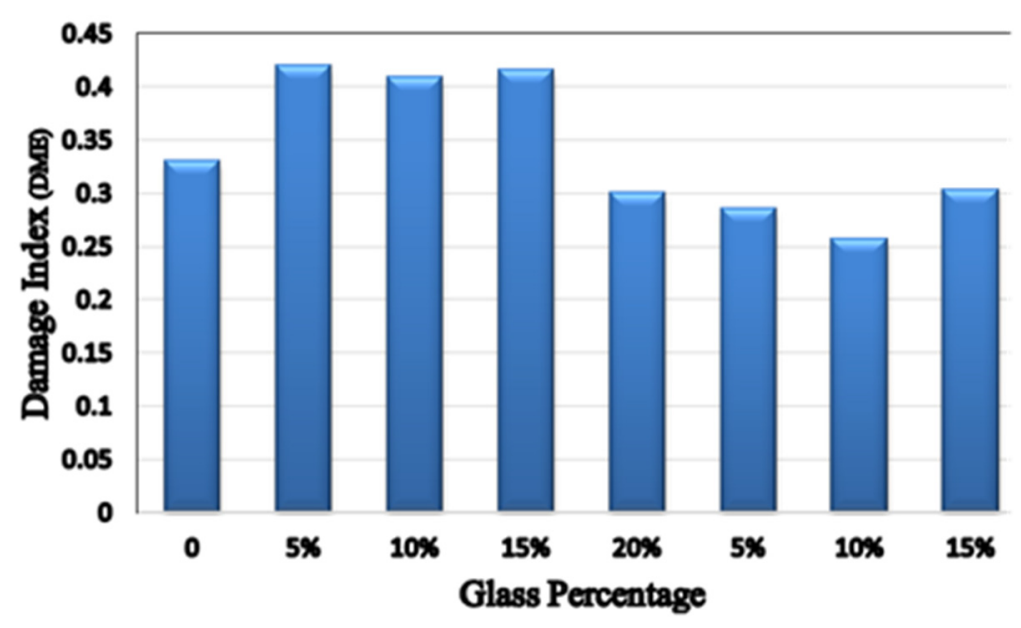

Figure 6. Damage Index of concrete prismscontaining different glass percentages which were exposed to the action of freezing and thawing cycles using the frequency resonance method (results are average of six specimens at each percentage)

\section{Conclusions}

The findings of this research indicate that using of glass waste in concrete can not only reduce problems encountered with environmental pollution, but also it may enhance the durability and mechanical properties of the concrete subjected to an environmental condition of freezing and thawing cycles. The following conclusions were drawn from the present work:

1) The compressive and flexural strengths of concrete were improved upon cement or fine aggregate replacement by glass waste at percentages of 10-20.

2) Incorporation of the glass waste partially in concrete improved its resistance against surface scaling upon exposure to freezing and thawing cycles. The best resistance was achieved when glass waste powder was used as a partial replacement of cement at a percentage of 10 .

3) The damage extent as evaluated by two different nondestructive techniques was decreased in concrete mixtures prepared at 10-20 percentages of glass waste replacement of cement or fine aggregates as compared to that of conventional concrete.

4) In general, the addition of crushed and milled glass wastes to the concrete mixtures can be considered not only a green solution, but also a method to enhance the mechanical properties and the durability of concrete mixtures.

\section{Acknowledgments}

The writers would like to thank the Applied Science University for their supporting and funding the research work.

\section{References}

American Psychological Association. (1972). Ethical standards of psychologists. Washington, DC: American Psychological Association.

Bazant, Z., \& Mayer, C. (1998). Fracture mechanics of concrete structures. Proceedings of fracture mechanics: part 3 (pp. 1687-1693).

Carpenter, A., \& Cramer, S. (1999). Mitigation of alkali-silica reaction in pavement patch concrete that incorporates highly reactive fine aggregate. Transportation Research Record: Journal of the Transportation Research Board, (1668), 60-67. 
Federico, L. M., \& Chidiac, S. E. (2009). Waste glass as a supplementary cementitious material in concretecritical review of treatment methods. Cement and concrete composites, 31(8), 606-610. http://dx.doi.org/10. 1016/j.cemconcomp.2009.02.001

Ismail, Z. Z., \& Al-Hashmi, E. A. (2009). Recycling of waste glass as a partial replacement for fine aggregate in concrete. Waste management, 29(2), 655-659.

Kim, J., Moon, J. H., Shim, J. W., Sim, J., Lee, H. G., \& Zi, G. (2014). Durability properties of a concrete with waste glass sludge exposed to freeze-and-thaw condition and de-icing salt. Construction and Building Materials, 66, 398-402. http://dx.doi.org/10.1016/j.conbuildmat.2014.05.081

Ling, T. C., Poon, C. S., \& Wong, H. W. (2013). Management and recycling of waste glass in concrete products: Current situations in Hong Kong. Resources, Conservation and Recycling, 70, 25-31. http://dx.doi.org/10. 1016/j.resconrec.2012.10.006

Madandoust, R., \& Ghavidel, R. (2013). Mechanical properties of concrete containing waste glass powder and rice husk ash. Biosystems Engineering, 116(2), 113-119. http://dx.doi.org/10.1016/j.biosystemseng.2013. 07.006

Metwally, I. (2007). Investigations on the performance of concrete made with blended finely milled waste glass. Advances in Structural Engineering, 10(1), 47-53. http://dx.doi.org/10.1260/136943307780150823

Pattengil, M., \& Shutt, T. C. (1973). Use of ground glass as a pozzolan. In Albuquerque symposium on utilization of waste glass in secondary products. New Mexico, USA.

Saikia, N., \& de Brito, J. (2014). Mechanical properties and abrasion behaviour of concrete containing shredded PET bottle waste as a partial substitution of natural aggregate. Construction and Building Materials, 52, 236-244. http://dx.doi.org/10.1016/j.conbuildmat.2013.11.049

Saribiyik, M., Piskin, A., \& Saribiyik, A. (2013). The effects of waste glass powder usage on polymer concrete properties. Construction and Building Materials, 47, 840-844.

Schmidt, A., \& Saia, W. H. F. (1963). Alkali-aggregate reaction tests on glass used for exposed aggregate wall panel work. ACI Mater J, 60, 1235-1236.

Shi, C., \& Zheng, K. (2007). A review on the use of waste glasses in the production of cement and concrete. Resources, Conservation and Recycling, 52(2), 234-247. http://dx.doi.org/10.1016/j.resconrec.2007.01.013

Soroushian, P. (2012). Strength and durability of recycled aggregate concrete containing milled glass as partial replacement for cement. Construction and Building Materials, 29, 368-377. http://dx.doi.org/10.1016/j. conbuildmat.2011.10.061

Taha, B., \& Nounu, G. (2008). Properties of concrete contains mixed colour waste recycled glass as sand and cement replacement. Construction and Building Materials, 22(5), 713-720. http://dx.doi.org/10.1016/j. conbuildmat.2007.01.019

Topcu, I. B., \& Canbaz, M. (2004). Properties of concrete containing waste glass. Cement and Concrete Research, 34(2), 267-274. http://dx.doi.org/10.1016/j.cemconres.2003.07.003

Tuan, B. L. A., Hwang, C. L., Lin, K. L., Chen, Y. Y., \& Young, M. P. (2013). Development of lightweight aggregate from sewage sludge and waste glass powder for concrete. Construction and Building Materials, 47, 334-339. http://dx.doi.org/10.1016/j.conbuildmat.2013.05.039

\section{Copyrights}

Copyright for this article is retained by the author(s), with first publication rights granted to the journal.

This is an open-access article distributed under the terms and conditions of the Creative Commons Attribution license (http://creativecommons.org/licenses/by/3.0/). 